Article

\title{
Regional Intestinal Drug Permeability and Effects of Permeation Enhancers in Rat
}

\author{
David Dahlgren ${ }^{1}\left(\mathbb{D}\right.$, Maria-Jose Cano-Cebrián ${ }^{2} \mathbb{D}$, Tobias Olander ${ }^{1}$, Mikael Hedeland ${ }^{3,4}$, \\ Markus Sjöblom ${ }^{5}$ and Hans Lennernäs ${ }^{1, *}$ \\ 1 Department of Pharmacy, Division of Biopharmaceutics, Uppsala University, 75236 Uppsala, Sweden; \\ david.dahlgren@farmaci.uu.se (D.D.); olander92@hotmail.com (T.O.) \\ 2 Department of Pharmacy and Pharmaceutical Technology and Parasitology, University of Valencia, \\ 46010 València, Spain; Maria.Jose.Cano@uv.es \\ 3 Department of Medicinal Chemistry, Analytical Pharmaceutical Chemistry, Uppsala University, \\ 75236 Uppsala, Sweden; mikael.hedeland@ilk.uu.se \\ 4 Department of Chemistry, Environment and Feed Hygiene, National Veterinary Institute (SVA), \\ 75189 Uppsala, Sweden \\ 5 Department of Neuroscience, Division of Physiology, Uppsala University, 75236 Uppsala, Sweden; \\ Markus.Sjoblom@neuro.uu.se \\ * Correspondence: hans.lennernas@farmaci.uu.se
}

Received: 23 January 2020; Accepted: 3 March 2020; Published: 8 March 2020

\begin{abstract}
Sufficient colonic absorption is necessary for all systemically acting drugs in dosage forms that release the drug in the large intestine. Preclinically, colonic absorption is often investigated using the rat single-pass intestinal perfusion model. This model can determine intestinal permeability based on luminal drug disappearance, as well as the effect of permeation enhancers on drug permeability. However, it is uncertain how accurate the rat single-pass intestinal perfusion model predicts regional intestinal permeability and absorption in human. There is also a shortage of systematic in vivo investigations of the direct effect of permeation enhancers in the small and large intestine. In this rat single-pass intestinal perfusion study, the jejunal and colonic permeability of two low permeability drugs (atenolol and enalaprilat) and two high-permeability ones (ketoprofen and metoprolol) was determined based on plasma appearance. These values were compared to already available corresponding human data from a study conducted in our lab. The colonic effect of four permeation enhancers-sodium dodecyl sulfate, chitosan, ethylenediaminetetraacetic acid (EDTA), and caprate- - on drug permeability and transport of chromium EDTA (an established clinical marker for intestinal barrier integrity) was determined. There was no difference in jejunal and colonic permeability determined from plasma appearance data of any of the four model drugs. This questions the validity of the rat single-pass intestinal perfusion model for predicting human regional intestinal permeability. It was also shown that the effect of permeation enhancers on drug permeability in the colon was similar to previously reported data from the rat jejunum, whereas the transport of chromium EDTA was significantly higher $(p<0.05)$ in the colon than in jejunum. Therefore, the use of permeation enhancers for increasing colonic drug permeability has greater risks than potential medical rewards, as indicated by the higher permeation of chromium EDTA compared to the drugs.
\end{abstract}

Keywords: regional intestinal permeability; permeation enhancers; absorption-modifying excipients; oral peptide delivery; intestinal perfusion; pharmaceutical development

\section{Introduction}

The rat single-pass intestinal perfusion (SPIP) model investigates epithelial membrane permeability, a key biopharmaceutical variable in drug absorption following oral intake [1]. The model is therefore 
frequently used in pharmaceutical development to evaluate the potential success of a drug, for instance with oral modified-release (MR) dosage forms. In MR dosage forms, the drug is released throughout the gastrointestinal (GI) tract prior to absorption so the regional intestinal permeability needs to be sufficiently high in both the small and large intestine. The rat and human small intestine have similar drug intestinal absorption profiles and transporter expression patterns, but differ in their enzymatic metabolism [2]. Differences in absorption from the rat and human colon have not been extensively compared, but a recent meta-analysis of rat SPIP data reports regional differences in drug permeability for 42 drugs in this species [3].

How relevant for humans are the regional intestinal drug permeability values determined in the rat SPIP model? It is difficult to answer this because of the limited amount of human reference permeability data from the lower GI tract (colon), and inter-laboratory variability in permeability determinations using the rat SPIP model $[3,4]$. Foremost, it is inherently difficult to accurately determine the luminal disappearance of medium-to-low permeability drugs in the SPIP model. Permeability is often overestimated for drugs with a low permeability because differences in the perfusate concentrations entering and leaving the perfused segment may be too small for accurate quantification. To circumvent this problem for low-permeation compounds, the drug permeability can be determined on the basis of plasma appearance data of intact drug (corrected for first-pass extraction) [5]. For instance, a recent study in the rat jejunum showed that the permeability value of the low permeability drugs atenolol and enalaprilat was $>10$ times higher in the same rat when determined from luminal disappearance, compared to plasma appearance [5]. In the same rat study, as well as in a human study, there were no differences for the high-permeability compounds metoprolol and ketoprofen. Thus, the choice of determination method seems to be important only for low-permeation compounds [4]. Accordingly, there is need for an evaluation of the human in vivo predictive relevance of regional intestinal drug permeability values determined from plasma appearance in the rat SPIP model.

The rat SPIP model may also be used to investigate regional intestinal differences in how pharmaceutical excipient(s) affect drug permeation and overall absorption rate. This is especially relevant because of the renewed interest in permeation enhancers (PE), also called absorption-modifying excipients (AME), for enabling oral administration of low-permeation compounds, for example, peptides [6,7]. Some advocates of this formulation approach propose the colon as a potential target for PEs, because the colon has a longer residence time, its mucosa may be more easily affected, and it does not have the higher peptidase activity of the upper GI tract [8,9].

However, few comparisons of the small and large intestine in rat have been made on the direct permeability effects of PEs in the same laboratory. Even fewer comparisons have used in vivo models, which are substantially more resilient to intestinal PE effects than in vitro models such as cell- and tissue-based systems [10]. Accordingly, there is a need for a systematic evaluation of PE effects in the small and large intestine in the more relevant in vivo permeability models, such as SPIP.

The primary objective of this rat SPIP study was to investigate the regional intestinal differences (jejunum vs colon) in lumen-to-blood drug permeability, as determined from plasma appearance data. Permeability values were determined at both $\mathrm{pH} 6.5$ and 7.4 for two low permeability model drugs (atenolol and enalaprilat) and for two high-permeation ones (ketoprofen and metoprolol). The second objective was to evaluate the relevance of the rat model, by comparing the regional intestinal permeability values with reported values of three model drugs (not enalaprilat) in human, as determined from plasma drug appearance. The third objective was to investigate the effect in the rat colon of four PEs with different mechanisms of action: sodium dodecyl sulfate (SDS), chitosan, ethylenediaminetetraacetic acid (EDTA), and sodium caprate. These four PEs have previous rat jejunal reference values at the same luminal concentrations determined at our laboratory [11,12]. The PE effects were evaluated based on changes in permeability of the four model drugs, and in blood-to-lumen clearance of ${ }^{51}$ chromium-labeled ethylenediaminetetraacetate (CL $L_{\text {-EDTA }}$ ), an established clinical marker for mucosal barrier integrity [13]. 


\section{Materials and Methods}

\subsection{Active Pharmaceutical Ingredients, Pharmaceutical Excipients and Other Chemicals}

Four model compounds were selected: atenolol, enalaprilat, ketoprofen, and metoprolol. Biopharmaceutical classification (BCS) and some physicochemical properties for the four drugs are summarized in Table 1. Four PEs with different mechanisms of action were selected: SDS (anionic surfactant), sodium caprate (fatty acid), chitosan (polysaccharide), and EDTA (chelating agent). Atenolol and metoprolol tartrate were provided by AstraZeneca AB (Mölndal, Sweden). Enalaprilat, ketoprofen, sodium caprate, SDS, bovine albumin (A2153), EDTA, and inactin (thiobutabarbital) were purchased from Sigma-Aldrich (St. Louis, MO, USA). Sodium phosphate dibasic dihydrate $\left(\mathrm{Na}_{2} \mathrm{HPO}_{4} \cdot 2 \mathrm{H}_{2} \mathrm{O}\right)$, potassium dihydrogen phosphate $\left(\mathrm{KH}_{2} \mathrm{PO}_{4}\right)$, sodium hydroxide $(\mathrm{NaOH})$, and sodium chloride $(\mathrm{NaCl})$ were purchased from Merck KGaA (Darmstadt, Germany). ${ }^{51} \mathrm{Cr}$-EDTA was purchased from PerkinElmer Life Sciences (Boston, MA, USA). Chitosan hydrochloride (molecular mass 40-300 kDa, degree of acetylation 8.8\%) was purchased from Kraeber and Co GmbH (Ellerbek, Germany). Parecoxib (dynastat) was obtained from Apoteket AB, Uppsala, Sweden.

Table 1. Some physicochemical properties and Biopharmaceutics Classification System (BCS) classification of the four model drugs [14].

\begin{tabular}{cccccccc}
\hline Compounds (BCS Class) & MM (g/mol) & pK $_{\mathbf{a}}$ & PSA & HBA/HBD & Log P & Log D & Log D \\
\hline Atenolol (III) & 266 & $9.6^{\mathrm{b}}$ & 88.1 & $4 / 4$ & 0.18 & -2.0 & $<-2.0$ \\
\hline Enalaprilat (III) & 348 & $3.17^{\mathrm{b}} / 7.84^{\mathrm{a}}$ & 102.1 & $6 / 3$ & -0.13 & -1.0 & -1.0 \\
\hline Metoprolol (I) & 267 & $9.6^{\mathrm{b}}$ & 57.8 & $4 / 2$ & 2.07 & 0.0 & -0.5 \\
\hline Ketoprofen (II) & 254 & $3.89^{\mathrm{a}}$ & 54.2 & $3 / 1$ & 3.37 & 0.1 \\
\hline
\end{tabular}

${ }^{a}$ acid, ${ }^{b}$ base, HBA/HBD—hydrogen bond acceptor/donor, Log $\mathrm{D}_{7.4 / 6.5}$-n-octanol-water partition coefficient at $\mathrm{pH}$

7.4/6.5, Log P—n-octanol-water coefficient, MM—-molar mass, pKa-dissociation constant, PSA—polar surface area.

\subsection{Study Formulations}

Eight isotonic (290 mOsm) phosphate-buffered perfusates were prepared, each containing all four drugs atenolol, enalaprilat, ketoprofen, and metoprolol at $100 \mu \mathrm{M}$. There were two control solutions at $\mathrm{pH} 6.5$ and 7.4 containing no PEs, and six test formulations containing PEs. The phosphate buffer strength was $8 \mathrm{mM}$ at $\mathrm{pH} 6.5$, and $80 \mathrm{mM}$ at pH 7.4 to avoid a reduction in $\mathrm{pH}$ during the perfusion. Five of the test formulations were perfused at $\mathrm{pH} 6.5$ and contained one of the following PEs in solution: SDS at 1 and $5 \mathrm{mg} / \mathrm{mL}$ (3.5 and $17.3 \mathrm{mM}$ ), EDTA at 1 and $5 \mathrm{mg} / \mathrm{mL}$ (3.4 and $17.1 \mathrm{mM})$, and chitosan at $5 \mathrm{mg} / \mathrm{mL}(\approx 30 \mu \mathrm{M})$. One of test formulations was perfused at $\mathrm{pH} 7.4$ and contained a suspension of sodium caprate at $10 \mathrm{mg} / \mathrm{mL}(51 \mathrm{mM})$. The higher $\mathrm{pH}$ in the perfusate was used for caprate as it has no permeation enhancing effect at $\mathrm{pH} 6.5$ in either the rat or human SPIP models, as its solubility is higher at pH 7.4 (2 vs. $5 \mathrm{mg} / \mathrm{mL}$ ) [11,15]. The PE concentrations of 1, 5, and $10 \mathrm{mg} / \mathrm{mL}$ correspond to oral doses of $0.2,1.0$, and $2.0 \mathrm{~g}$ administered with $200 \mathrm{~mL}$ water, as these values are previously shown to affect the intestinal permeability of low-permeation model compounds in the rat SPIP model [11,12].

The preparation procedure of the perfusion formulations $(100 \mathrm{~mL})$ is described in detail earlier [12]. No incompatibility, degradation, or apparent binding to glass/plastic of the study compounds in solution ( $\mathrm{pH} 6.5,37^{\circ} \mathrm{C}$ ) was observed during $4 \mathrm{~h}$. Osmolarity was determined (after addition of all perfusate constituents, e.g., salt, PE, water) by freezing-point depression using a Micro Osmometer (Model 3MO; Advanced Instruments, Needham Heights, MA, USA).

\subsection{Animals and Study Design}

The surgical procedure and experimental setup of the rat SPIP experiment has been previously described [12]. The study was approved by the local ethics committee for animal research (no: C64/16) in Uppsala, Sweden. In short, male Han Wistar rats (strain 273) from Charles River Co. (Cologne, Germany), weight 270-420 g, were used. On the study day, the rats were anesthetized using an 
intraperitoneal injection of a 5\% w/v inactin solution $(180 \mathrm{mg} / \mathrm{kg})$. Body temperature was maintained at $37.5 \pm 0.5^{\circ} \mathrm{C}$. Systemic arterial blood pressure was continuously recorded to validate the condition of the animal. This was done by connecting an arterial catheter to a transducer operating a PowerLab system (AD Instruments, Hastings, UK).

At the SPIP experiment, the abdomen was opened along the midline and a jejunal $(10-12 \mathrm{~cm})$ or colonic (6-12 cm) segment was cannulated, covered with polyethylene wrap, and placed outside the abdomen [5]. The bile duct was cannulated to avoid pancreaticobiliary secretion into the duodenum at the jejunal perfusion. After completion of surgery, ${ }^{51} \mathrm{Cr}$-EDTA was administered intravenously (iv) as a bolus of $75 \mu \mathrm{Ci}(0.4 \mathrm{~mL})$, followed by a continuous iv infusion at a rate of $50 \mu \mathrm{Ci}$ per hour $(1 \mathrm{~mL} / \mathrm{h})$ for the duration of the experiment. During the first $30 \mathrm{~min}$ following surgery, each small and large intestinal segment was single-passed perfused with $37^{\circ} \mathrm{C}$, phosphate-buffered saline $(6 \mathrm{mM})$ at $\mathrm{pH} 6.5$ or 7.4. This stabilized cardiovascular, respiratory, and intestinal functions and the ${ }^{51} \mathrm{Cr}$-EDTA levels in the blood (plasma). The length and wet tissue weight of each intestinal segment was determined after the experiment. The single-pass perfusion rate was at all times $0.2 \mathrm{~mL} / \mathrm{min}$ (peristaltic pump, Gilson Minipuls 3, Le Bel, France).

Each of the six PE experiments was performed in the colon and was divided into two parts. In the first part, the segment was perfused with the control buffer solution (containing model compounds but no PE) for $60 \mathrm{~min}$. In the second part, the segment was perfused for $75 \mathrm{~min}$ with one of the six test formulations, containing model compounds and one of the following PEs: SDS at $1 \mathrm{or} 5 \mathrm{mg} / \mathrm{mL}$, EDTA at 1 or $5 \mathrm{mg} / \mathrm{mL}$, chitosan at $5 \mathrm{mg} / \mathrm{mL}$ (pH 6.5), and caprate at $10 \mathrm{mg} / \mathrm{mL}$ (pH 7.4). The six PE experiments were designed so that each rat was its own control. For regional intestinal comparisons, all the above $\mathrm{PE}$ concentrations and $\mathrm{pH}$ values were previously evaluated in the jejunum, at our laboratory and using the same experimental design.

To evaluate regional intestinal differences in basal permeability values of the four model drugs, two perfusions were also performed in the jejunum using only the control solutions (no PE) for $60 \mathrm{~min}$, at $\mathrm{pH} 6.5$ and 7.4. This established a basal permeability value for comparison with the values determined in the control period of the PE experiments in the colon.

All experimental periods started with a rapid filling $(<30 \mathrm{~s})$ of the whole segment with the perfusate (about $1.5 \mathrm{~mL}$ for a $10-\mathrm{cm}$ segment). The intestinal segment and perfusates were kept at $37^{\circ} \mathrm{C}$ and all outgoing perfusate was quantitatively collected and weighed at 15 -min intervals.

Blood samples of $<0.3 \mathrm{~mL}$ were collected from the femoral artery for a maximum volume of $4 \mathrm{~mL}$ during each experiment. All sampled blood volumes were replaced by an equivalent volume of saline $(0.9 \% \mathrm{NaCl})$ solution with $70 \mathrm{mg} / \mathrm{mL}$ bovine serum albumin. Blood was sampled at $15-\mathrm{min}$ intervals for $135 \mathrm{~min}$ ( 9 samples) in each of the six PE experiments, and for $60 \mathrm{~min}$ (4 samples) in the jejunal controls. The blood samples were put on ice and centrifuged $\left(5000 \times g, 3 \mathrm{~min}\right.$ at $\left.4{ }^{\circ} \mathrm{C}\right)$ within $10 \mathrm{~min}$. $100 \mu \mathrm{L}$ of the plasma was transferred to $500 \mu \mathrm{L}$ microtubes and stored at $-20^{\circ} \mathrm{C}$ until analysis.

\subsection{Determination of Blood-to-Lumen Jejunal ${ }^{51} \mathrm{Cr}$-EDTA Clearance $\left(C L_{C r-E D T A}\right)$}

In the six PE experiments, all luminal perfusates and blood plasma were analyzed at 0 and $135 \mathrm{~min}$ for ${ }^{51} \mathrm{Cr}$ activity (cpm) in a gamma counter (1282 Compugamma CS, Pharmacia AB, Uppsala, Sweden). A linear regression analysis of the plasma samples was made to obtain a corresponding plasma value

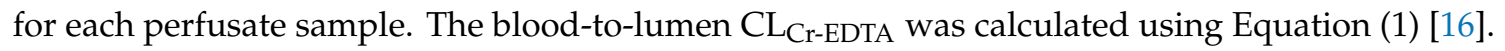

$$
C L_{C r-E D T A}=\frac{C_{\text {perfusate }} \times Q_{\text {in }}}{C_{\text {plasma }} \times \text { tissue weight }} \times 100
$$

where $C_{\text {perfusate }}$ and $C_{\text {plasma }}$ is the activity in the perfusate and plasma $(\mathrm{cpm} / \mathrm{mL})$, and $Q_{\text {in }}$ is the flow rate $(\mathrm{mL} / \mathrm{min})$. $\mathrm{CL}_{\mathrm{Cr} \text {-EDTA }}$ was determined during the last $45 \mathrm{~min}$ for the control solution and during the last $60 \mathrm{~min}$ for the test solutions, of which the first $15 \mathrm{~min}$ of each period were for equilibration. 
The mean $\mathrm{CL}_{\mathrm{Cr} \text {-EDTA }}$ value of the two perfusion periods was regarded as representative for each individual rat.

\subsection{Bioanalysis}

The plasma concentrations of atenolol, metoprolol, enalaprilat and ketoprofen were determined using Ultra-High Performance Liquid Chromatography coupled to Tandem Mass Spectrometry. The method used has been previously published [17]. The only modification was that the lower limit of quantification for ketoprofen was decreased to $52 \mathrm{nM}$ in this study.

\subsection{Intestinal Effective Permeability $\left(P_{\text {eff }}\right)$ Calculation}

Jejunal and colonic lumen-to-blood effective permeability $\left(\mathrm{P}_{\text {eff }}\right)$ of the four model compounds was determined based on a modification of the method described by Sjögren et al., 2015 [18]. This method has been successfully implemented in human, dog and rat [4,18-21]. In short, an input rate was acquired by deconvolution of the plasma concentration-time profiles following the intestinal perfusion using Phoenix software version 8.2 (Certara USA, Princeton, NJ, USA). Previous intravenous pharmacokinetic data from a two-compartment analysis of the model drugs in Han Wistar rats was used as impulse response in the deconvolution [12]. An absorption rate was then calculated by compensating for first-pass extraction ( $\mathrm{F}_{\text {firstpass }}$ ) of each compound in the rat intestine and liver. The $\mathrm{F}_{\text {firstpass }}$ values for atenolol (1.0), enalaprilat (0.99), ketoprofen (0.99), and metoprolol (0.22) were based on literature data for the fraction of the model compound as follows: (i) the amount metabolized/excreted in the rat liver; (ii) plasma CL values derived from the two-compartment analysis of the intravenous plasma data; and (iii) an assumed rat-liver blood flow of $47 \mathrm{~mL} / \mathrm{min} / \mathrm{kg}$ [22-24]. The $P_{\text {eff }}(\mathrm{cm} / \mathrm{s})$ was then calculated by relating the absorption rate to the intestinal luminal area using Equation (2):

$$
P_{e f f}=\frac{\text { absorption rate }}{A \times C}
$$

where $A$ is the area of the exposed intestinal segment described as a smooth cylinder with a radius of $0.2 \mathrm{~cm}$, and $\mathrm{C}$ is the concentration entering the luminal segment.

In the six colonic PE experiments, $P_{\text {eff }}$ was evaluated from 0 to 135 min and the mean $P_{\text {eff }}$ value of the two perfusion periods (60-min control and 75-min test) was regarded as representative for each individual rat. In the control experiments performed in jejunum, $P_{\text {eff }}$ was evaluated from 0 to $60 \mathrm{~min}$ and the mean $P_{\text {eff }}$ value was regarded as representative for each individual rat.

\subsection{Statistical Analysis}

The sample size in each study group was six rats, on the basis of power analysis and previous perfusion studies $[12,25]$. Plasma concentration, $\mathrm{P}_{\text {eff }}$, and $\mathrm{CL}_{\mathrm{Cr} \text {-EDTA }}$ values are expressed as mean \pm standard deviation (SD) or standard error of the mean (SEM). The jejunal vs colonic $\mathrm{P}_{\text {eff }}$ ratio, is presented as well as the $\mathrm{P}_{\text {eff }}$ and $\mathrm{CL}_{\mathrm{Cr} \text {-EDTA }}$ ratio between the 45-min control and 60-min test period in the six colonic PE perfusions (Equation (3)).

$$
\text { Ratio }\left(C L_{C r-E D T A} \text { or } P_{\text {eff }}\right)=\frac{\text { mean value }(\text { jejunum or test period })}{\text { mean value }(\text { colon or control period })}
$$

The ratio was compared using the paired student's t-test with the Benjamini-Hochberg multiple $\mathrm{t}$-test correction. Multiple comparisons between groups were performed using a two-way ANOVA with a post-hoc Holm-Sidak multiple comparison test. Log transformation of values was performed when the original measured data were heteroscedastic and not normally distributed; this was investigated using the Bartlett test. Differences were considered to be statistically significant for $p$-values $<$ than 0.05 . 


\section{Results}

\subsection{Plasma Profiles}

The mean $( \pm$ SEM) plasma concentration-time profiles are presented in Figure 1a-d for atenolol, enalaprilat, ketoprofen, and metoprolol following the jejunal and colonic perfusions (first $60 \mathrm{~min}$ ) of the control solutions at $\mathrm{pH} 6.5$ and 7.4. These plasma concentration-time data for the selected model drugs were used to determine regional intestinal basal $\mathrm{P}_{\text {eff }}$ values using Equation (2).
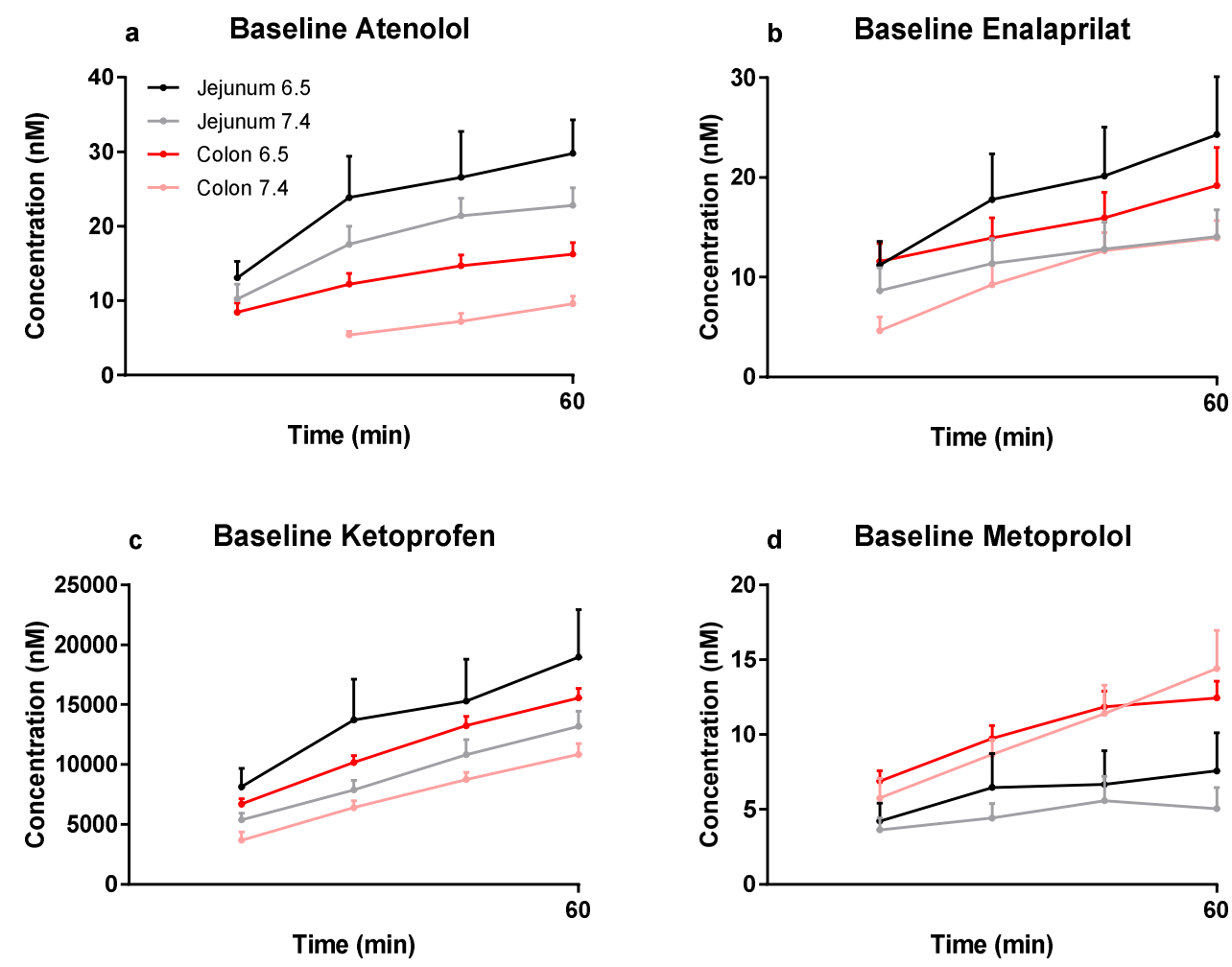

Figure 1. The mean \pm SEM rat plasma concentration-time profiles $(n=30$ for colon at $\mathrm{pH} 7.4$, and $n=6$ for the other three groups) of: (a) atenolol, (b) enalaprilat, (c) ketoprofen, and (d) metoprolol following single-pass jejunal and colonic perfusions of the $\mathrm{pH} 6.5$ and 7.4 control solutions (0-60 min). These plasma data were used to determine regional intestinal basal $\mathrm{P}_{\text {eff }}$ values using Equation (2) (Table 2).

The mean $( \pm$ SEM) plasma concentration-time profiles are presented in Figure 2a-d for atenolol, enalaprilat, ketoprofen, and metoprolol after: (i) the colonic perfusions of the control solutions (0-60 min), and (ii) then followed by the six PE-containing test formulations (60-135 min). These plasma concentration-time data were used to determine the PE-induced increase in $\mathrm{P}_{\text {eff }}$ ratio (test/control period) using Equation (3).

\subsection{Lumen-to-Blood Effective Permeability $\left(P_{\text {eff }}\right)$ of Model Drugs}

The mean $\left( \pm\right.$ SEM) basal jejunal and colonic $\mathrm{P}_{\text {eff }}$ at $\mathrm{pH} 6.5$ and $\mathrm{pH} 7.4$ are presented in Table 2 for atenolol, enalaprilat, ketoprofen, and metoprolol. There were no statistical $(p<0.05)$ differences in basal permeability for any of the model drugs at either $\mathrm{pH}$ or in any intestinal segment.

The mean $\mathrm{P}_{\mathrm{eff}}$ ratio between the jejunum and colon of atenolol (1.5), enalaprilat (0.6), ketoprofen (1.3), and metoprolol (0.7) at pH 6.5 are presented in Figure 3. For species comparison, Figure 3 also contains the previously published human/dog $\mathrm{P}_{\text {eff }}$ ratio between the jejunum and colon for atenolol (35/5), enalaprilat (not available/8), ketoprofen (2.6/1.0), and metoprolol (1.3/1.5) at pH 6.5 (plasma appearance data) $[4,19]$. 

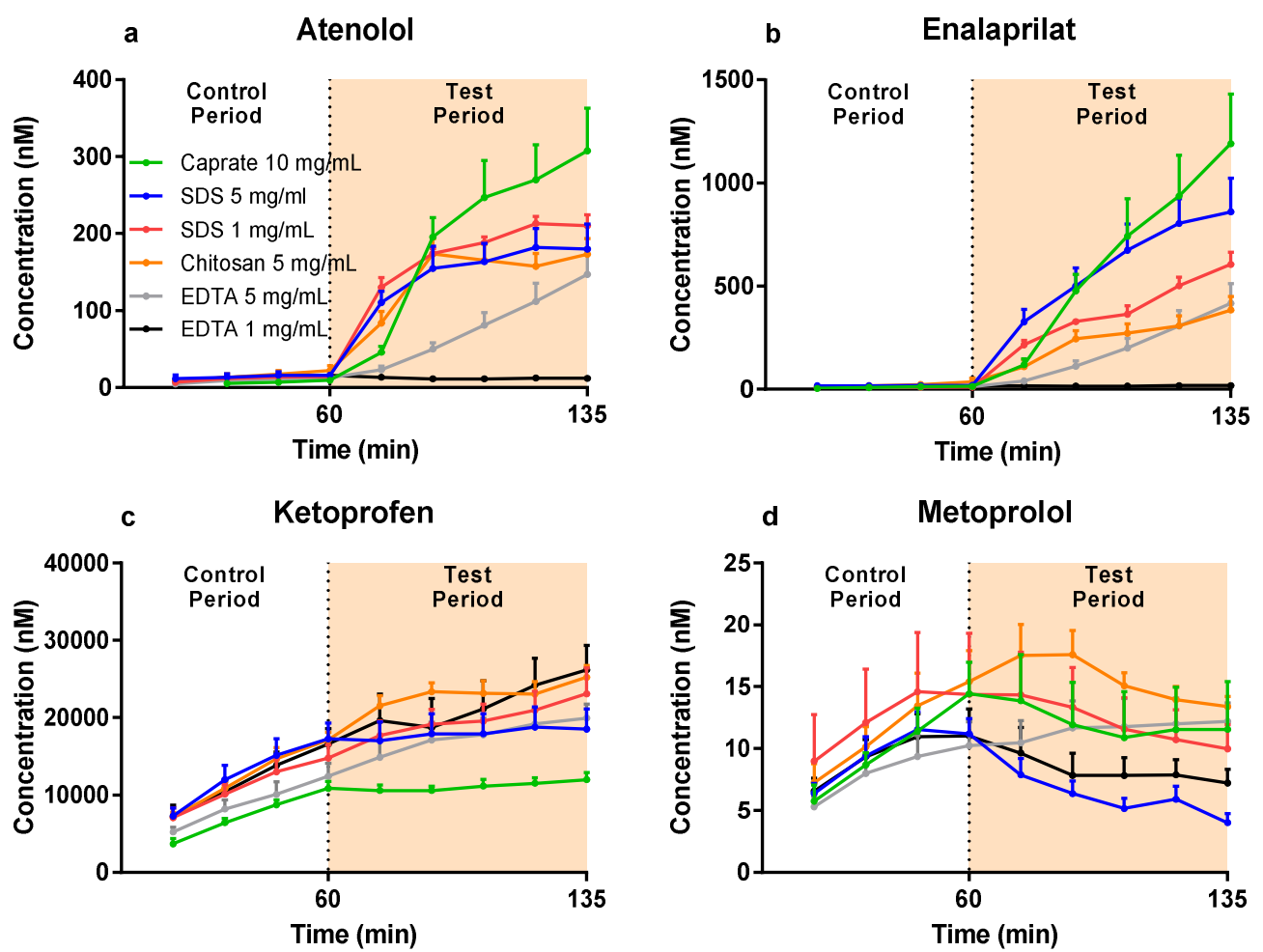

Figure 2. The mean \pm SEM rat colonic plasma concentration-time profiles $(n=6)$ of: (a) atenolol, (b) enalaprilat, (c) ketoprofen, and (d) metoprolol following single-pass intestinal perfusions of a control solution for $60 \mathrm{~min}$, followed by a 75-min perfusion of any of six test formulations containing a permeation enhancer (PE). The control solution and all test formulations contained $100 \mu \mathrm{M}$ atenolol, enalaprilat, ketoprofen, and metoprolol. The control and test formulation perfusate $\mathrm{pH}$ was 6.5 for the PEs: sodium dodecyl sulfate (SDS) at 1 and $5 \mathrm{mg} / \mathrm{mL}$, chitosan at $5 \mathrm{mg} / \mathrm{mL}$, and ethylenediaminetetraacetic acid (EDTA) at 1 and $5 \mathrm{mg} / \mathrm{mL}$. The control and test formulation perfusate $\mathrm{pH}$ was 7.4 for caprate at $10 \mathrm{mg} / \mathrm{mL}$. All formulations were solutions, except caprate which was a suspension (its solubility at $\mathrm{pH} 7.4$ is $5 \mathrm{mg} / \mathrm{mL}$ ).

Table 2. The mean $\pm \mathrm{SD}$ rat permeability $\left(\mathrm{P}_{\text {eff }}\right)$ values for the four model compounds determined in the jejunum and colon at $\mathrm{pH} 6.5$ and $7.4(n=6)$.

\begin{tabular}{ccccc}
\hline \multirow{2}{*}{ Conditions } & \multicolumn{4}{c}{ Plasma Appearance $\mathbf{P}_{\mathbf{e f f}}\left(\times \mathbf{1 0}^{\mathbf{4}} \mathbf{~ c m} / \mathbf{s}\right)$} \\
\cline { 2 - 5 } & Atenolol & Enalaprilat & Ketoprofen & Metoprolol \\
\hline Jejunum pH 6.5 & $0.022 \pm 0.01$ & $0.005 \pm 0.004$ & $1.5 \pm 1.1$ & $0.28 \pm 0.24$ \\
\hline Jejunum pH 7.4 & $0.016 \pm 0.005$ & $0.004 \pm 0.001$ & $0.64 \pm 0.15$ & $0.17 \pm 0.095$ \\
\hline Colon pH 6.5 & $0.015 \pm 0.007$ & $0.009 \pm 0.007$ & $1.1 \pm 0.3$ & $0.41 \pm 0.19$ \\
\hline Colon pH 7.4 & $0.011 \pm 0.005$ & $0.006 \pm 0.004$ & $0.73 \pm 0.14$ & $0.38 \pm 0.15$ \\
\hline
\end{tabular}

The mean $( \pm S E M) P_{\text {eff }}$ ratio of the test and control periods for the six test formulations in the colon are shown in Figure $4 \mathrm{a}-\mathrm{d}$ for atenolol, enalaprilat, ketoprofen, and metoprolol. Figure 4a-d (blue symbols) also contains previous jejunal $\mathrm{P}_{\text {eff }}$ ratio data of atenolol, enalaprilat, and ketoprofen for chitosan at $5 \mathrm{mg} / \mathrm{mL}$, and for SDS at 1 and $5 \mathrm{mg} / \mathrm{mL}$ (and for enalaprilat with caprate at $10 \mathrm{mg} / \mathrm{mL}$ ) [11,12]. The colon seems to be more sensitive than the jejunum to caprate at $10 \mathrm{mg} / \mathrm{mL}$, as the $P_{\text {eff }}$ ratio of enalaprilat was significantly $(p<0.05)$ higher in the colon. There were no statistical differences between intestinal segments for any of the other model drugs and PEs. 


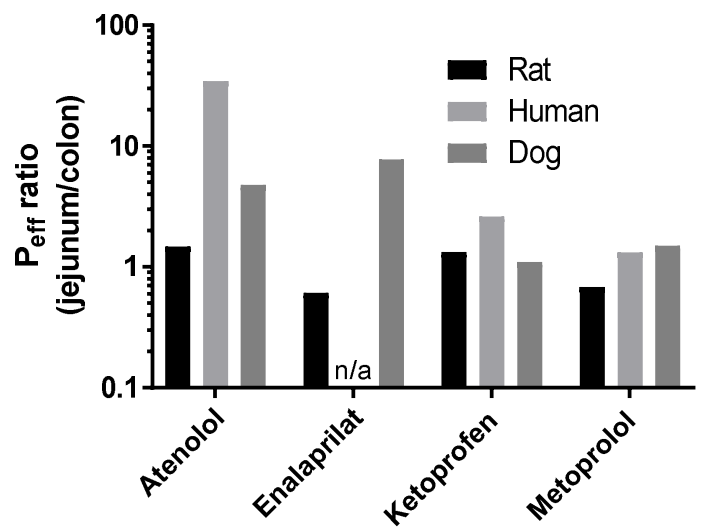

Figure 3. The $\mathrm{P}_{\text {eff }}$ ratio between the jejunum and colon at $\mathrm{pH} 6.5$ in rat of atenolol, enalaprilat, ketoprofen, and metoprolol (Table 2). The historical human and dog $\mathrm{P}_{\text {eff }}$ ratios between the jejunum and colon at $\mathrm{pH} 6.5$ of atenolol, enalaprilat (not human), ketoprofen, and metoprolol are also presented for species comparison [4,19].
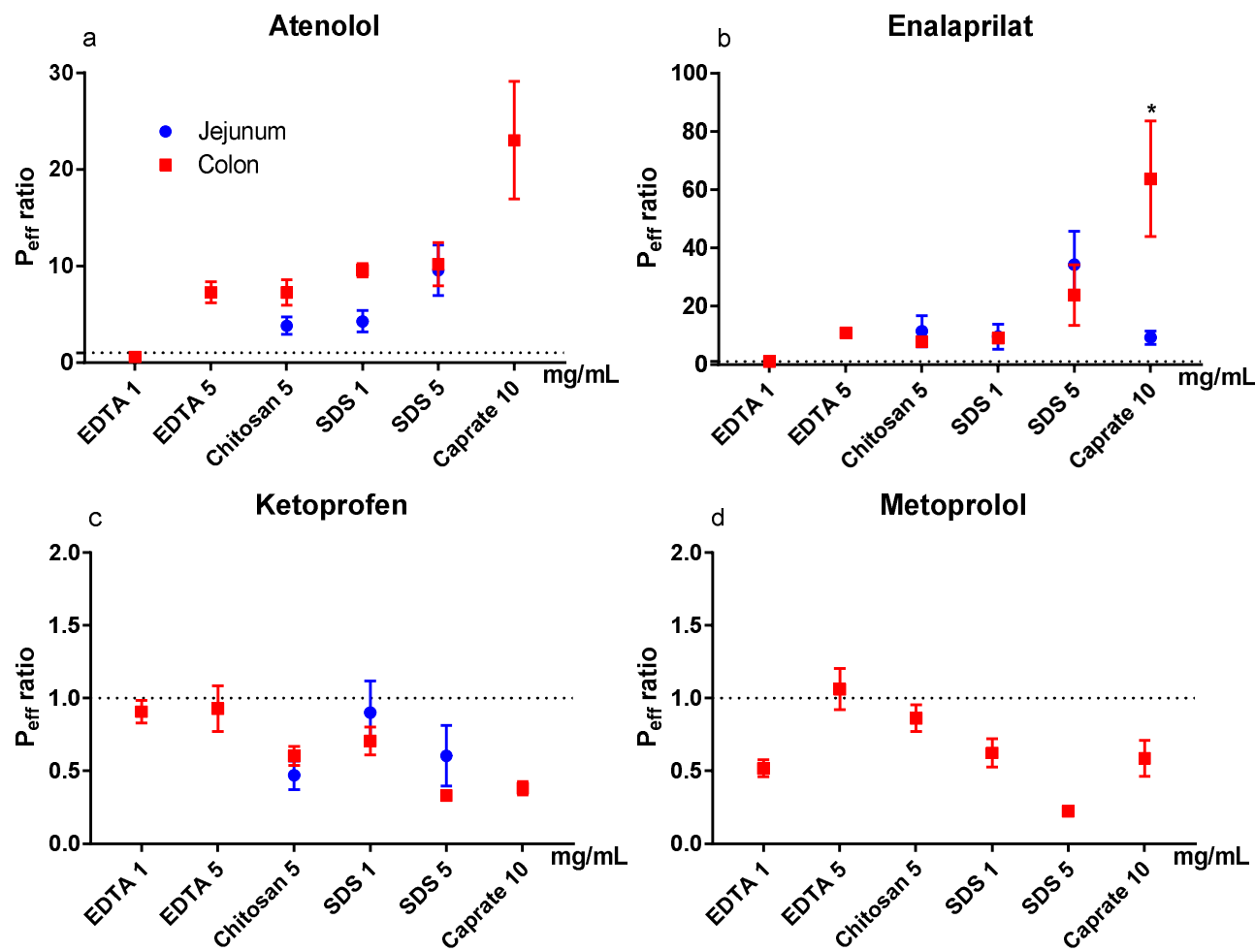

Figure 4. The mean \pm SEM rat jejunal (historical data) and colonic lumen-to-blood intestinal effective permeability $\left(\mathrm{P}_{\text {eff }}\right)$ ratio $(n=6)$ of: $(\mathbf{a})$ atenolol, $(\mathbf{b})$ enalaprilat, $(\mathbf{c})$ ketoprofen, and $(\mathbf{d})$ metoprolol, after intestinal perfusions of a control solution for $60 \mathrm{~min}$, followed by a 75-min perfusion of any of six permeation enhancing (PE) test formulations [11,12]. The control and test formulation perfusate $\mathrm{pH}$ was 6.5 for the PEs: sodium dodecyl sulfate (SDS) at 1 and $5 \mathrm{mg} / \mathrm{mL}$, chitosan at $5 \mathrm{mg} / \mathrm{mL}$, and ethylenediaminetetraacetic acid (EDTA) at 1 and $5 \mathrm{mg} / \mathrm{mL}$. The control and test formulation perfusate $\mathrm{pH}$ was 7.4 for caprate at $10 \mathrm{mg} / \mathrm{mL}$. All formulations were solutions, except caprate which was a suspension (its solubility at pH 7.4 is $5 \mathrm{mg} / \mathrm{mL}$ ). There is no jejunal historical data for metoprolol and only jejunal historical data for EDTA and caprate for enalaprilat. A * represents a significant difference in jejunal and colonic $\mathrm{P}_{\text {eff }}$ (two-way ANOVA, Holm-Sidak). 


\subsection{Blood-to-Lumen $C L_{C r-E D T A}$ Ratio}

The mean $( \pm S D)$ colonic $C_{C r-E D T A}$ for the control solutions $(n=38)$ was $0.038 \pm 0.050 \mathrm{~mL} / \mathrm{min} / 100 \mathrm{~g}$. The mean $( \pm S E M) C L_{C r-E D T A}$ ratios between the control and test period for the six test formulations in the colon (and for previously reported jejunal data, blue symbols) are shown in Figure 5. Unlike the $\mathrm{P}_{\text {eff }}$ ratios, there was a significant $\mathrm{PE}$-induced increase in $\mathrm{CL}_{\mathrm{Cr} \text {-EDTA }}$ ratio in the colon compared to the control for all test formulations, except EDTA at $1 \mathrm{mg} / \mathrm{mL}$. The increases were also significantly higher in the colon than in the jejunum for all test formulations.

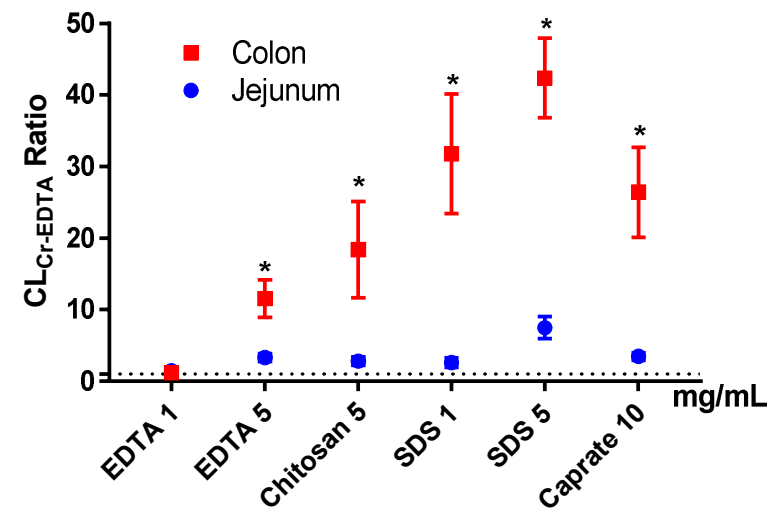

Figure 5. The mean \pm SEM rat jejunal (historical data) and colonic blood-to-lumen ${ }^{51} \mathrm{Cr}$-EDTA clearance $\left(\mathrm{CL}_{\mathrm{Cr} \text {-EDTA }}\right)$ ratio $(n=6)$, after intestinal perfusions of a control solution for $60 \mathrm{~min}$, followed by a 75-min perfusion of any of six permeation enhancing (PE) test formulations. The control and test formulation perfusate $\mathrm{pH}$ was 6.5 for the PEs: sodium dodecyl sulfate (SDS) at 1 and $5 \mathrm{mg} / \mathrm{mL}$, chitosan at $5 \mathrm{mg} / \mathrm{mL}$, and ethylenediaminetetraacetic acid (EDTA) at 1 and $5 \mathrm{mg} / \mathrm{mL}$. The control and test formulation perfusate $\mathrm{pH}$ was 7.4 for caprate at $10 \mathrm{mg} / \mathrm{mL}$. All formulations were solutions, except caprate which was a suspension (its solubility at $\mathrm{pH} 7.4$ is $5 \mathrm{mg} / \mathrm{mL}$ ). A * represents a significant difference in jejunal and colonic $\mathrm{CL}_{\mathrm{Cr}-\mathrm{EDTA}}$ ratio (two-way ANOVA, Holm-Sidak).

\section{Discussion}

This rat single-pass intestinal perfusion (SPIP) study is part of a sequence of mechanistic studies to evaluate regional intestinal differences in drug absorption in different species and models. The study also evaluates the in vivo effect of permeation enhancers (PEs) on intestinal transport of model drugs/peptides and marker compounds [12,25-27]. The primary objective was to investigate the regional intestinal differences in lumen-to-blood effective drug permeability $\left(\mathrm{P}_{\mathrm{eff}}\right)$ - as determined from plasma appearance data in the rat SPIP model-and to compare it to corresponding historical human data [4]. $P_{\text {eff }}$ was determined for two low-permeation model drugs, atenolol and enalaprilat, and for two high-permeation drugs, ketoprofen and metoprolol.

The secondary objective was to evaluate the effect of PEs on drug permeability in the rat colon, compared to previous jejunal data. The effects were evaluated based on model drug $P_{\text {eff }}$ and blood-to-lumen clearance of ${ }^{51} \mathrm{Cr}$-EDTA $\left(\mathrm{CL}_{\mathrm{Cr} \text {-EDTA }}\right)$, an established clinical marker for mucosal barrier integrity.

A modified-release (MR) dosage form can be used to optimize plasma pharmacokinetics, dosage regimens, and improve clinical performance. MRs enable once-per-day drug administration, reduce side effects, and increase patient compliance [28]. Successful development of such a dosage form requires that the drug be absorbed in all parts of the intestines, as drug release needs to be substantially longer than the typical human small intestinal transit time of 3-5 $\mathrm{h}$ [29]. Reliable preclinical data on regional intestinal permeability is therefore needed early in the development of any novel MR dosage form. The rat SPIP model is commonly used to determine regional permeability data on the basis of luminal drug disappearance. However, a recent meta-analysis shows wide variability in regional intestinal permeability data between studies and between laboratories. This raises the 
question how relevant individual studies on rats are for in vivo predictions in humans [3]. The lack of a correlation may be related to the method of drug permeability determination. A recent rat SPIP study demonstrated that the permeability values of the low permeability drugs, atenolol and enalaprilat, is 9 to 59 times higher when determined on the basis of luminal disappearance compared to plasma appearance [5]. Therefore, the primary aim of this study was to evaluate the suitability of the rat SPIP model for measurements of human regional intestinal drug permeability on the basis of plasma appearance data $[4,30]$.

In our study, there were only small differences in jejunal and colonic rat $\mathrm{P}_{\text {eff }}$ at $\mathrm{pH} 6.5$ for the high-permeability compounds, ketoprofen and metoprolol, when determined from plasma appearance. This is in good agreement with regional intestinal permeability data based on luminal disappearance in the rat SPIP model, as well as with human regional intestinal permeability data based on plasma appearance $[4,20,31]$. Our results show that the rat SPIP model accurately predicted regional differences (jejunum vs colon) in the permeability of high-permeability drugs, regardless whether these were determined by luminal disappearance or plasma appearance.

For the low permeability drugs, atenolol and enalaprilat, plasma appearance data showed no

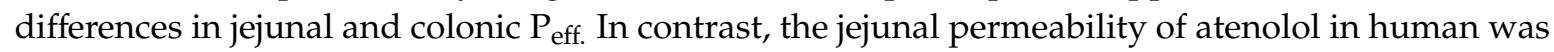
35 times higher than in colon. There is no reference value in human for enalaprilat, but in dog the corresponding jejunal value is eight-fold higher than the colonic permeability based on plasma appearance data [19]. Since the dog is well-known to have a colon that is much more permeable to drugs than that of human, presumably any reference value in human would result in a jejunal vs colonic ratio at least within the same order of magnitude as observed in dog [32]. Consequently, the plasma appearance of these two drugs suggests that the rat SPIP model is unable to accurately predict regional intestinal permeability of medium-to-low permeability drugs in human, which is also reported by others [33]. However, it should be emphasized that the rat SPIP model is still useful for evaluating a range of other biopharmaceutical, physiological, and biochemical processes. For instance, the rat jejunum is representative of human jejunal $\mathrm{P}_{\text {eff }}$ values determined from plasma appearance $[4,5]$. Therefore, the permeability data from the SPIP model will be useful for boundary BCS classification of permeability and for investigation of the potential effect of different concentrations of pharmaceutical excipients on local intestinal permeability [34].

There was a trend for a slightly higher (1.1- to 2.3-fold) jejunal and colonic permeability of all four model drugs at $\mathrm{pH} 6.5$ compared to 7.4. On the basis of the $\mathrm{pH}$-partitioning hypothesis, this was expected for the acid, ketoprofen, but not for the bases, atenolol and metoprolol [35]. These conflicting results indicate that parameters other than molecular charge dominate. For instance, passive membrane transport is also affected by paracellular pore selectivity, molecular elongation, and intramolecular hydrogen bonding, which might be better understood using complex molecular dynamic simulations [36]. Consequently, any $\mathrm{pH}$-dependent permeability values determined in the rat SPIP model should be interpreted with care, and a linear $\mathrm{pH}$-permeability relationship should not be used to predict intestinal drug transport and absorption.

Peptide drugs with a very low intestinal stability and/or permeability are, with a few exceptions, not administered orally because of their low intestinal absorption. Their low stability can be related to stomach $\mathrm{pH}$ denaturation, the high concentrations of luminal gastric and pancreatic peptidases and proteinases, and the high peptidase activity in the brush border membrane of the enterocytes [7]. These issues can be partly circumvented by the formulation approaches. For instance, (1) enteric coating can prevent gastric chemical instability and peptide degradation; the (2) proteinase/peptidase inhibitors in the formulation can increase the local luminal stability of the drug; and (3) drug release may be targeted to the colon where peptidase activity tends to be lower than in the small intestine $[9,37,38]$.

The low intestinal permeability of most peptides is related to their large size, low lipophilicity, and extensive hydrogen binding, all of which are physicochemical properties that predict low passive membrane transport [39]. A strategy to circumvent low intestinal permeability was recently approved for the first time in an oral product, for which a PE increased the intestinal membrane transport of 
semaglutide, a pharmaceutical peptide containing 31 amino acids, even though the bioavailability in dog is as low as $0.29 \%$ of the oral dose (data from patent: wo2012080471) [6]. The use of PEs has also been proposed in the colon, as the low luminal volumes and long transit time allow for high local mucosal PE concentrations at extended exposure times. Together these increase the likelihood of a positive effect on peptide membrane permeation. Accordingly, rat luminal instillation studies report a generally higher effect of PE in the colon than the jejunum on the plasma exposure of various molecular probes and peptides [8,40-44]. However, the rat luminal instillation model does not differentiate between PE effects on membrane permeability, and on transit/motility, dilution, and hydrodynamics in the luminal segment. This is in contrast to the SPIP model in which luminal and experimental conditions are controlled [10]. Therefore, our study performed a systematic evaluation of the effect of four permeation enhancers with different mechanisms of action at different luminal concentrations in colon.

In our rat SPIP study, all PEs (except EDTA at $1 \mathrm{mg} / \mathrm{mL}$ ) increased the $P_{\text {eff }}$ of the two low permeability drugs, atenolol and enalaprilat. However, for the vast majority of the PEs in this study, the increase in $P_{\text {eff }}$ ratio was not different from what we have previously observed in the jejunum in our laboratory [11,12]. This is in stark contrast to the significantly higher effect of all PEs in this study on $\mathrm{CL}_{\mathrm{Cr} \text {-EDTA }}$ ratio in the colon compared to the jejunum. The substantially higher effect on the transport of the clinical marker for mucosal integrity and damage, compared to drug absorption, indicates a greater risk for tissue damage than medical benefit in using PE for increasing colonic drug absorption. On the basis of the data from our study, we agree with other reports that the rationale is weak for colonic targeting of systemically acting drugs/peptides in combination with PEs [45].

In conclusion, this rat SPIP study showed no difference in jejunal and colonic permeability determined from plasma appearance data of two low permeability model compounds (atenolol and enalaprilat) and two high-permeability ones (ketoprofen and metoprolol). Comparison of these data with previous human data challenges ability of the rat SPIP model for predicting differences in human regional intestinal permeability of low-to-medium permeability drugs. The effect of PEs on drug permeability in the colon was similar to previously reported data from the rat jejunum. In contrast, their effect on the transport of Cr-EDTA — a clinical marker for mucosal barrier integrity—was significantly higher in the colon than in jejunum. These results indicate that the risk of using PE for increasing colonic drug permeability is higher than the potential medical reward.

Author Contributions: Conceptualization, D.D., M.-J.C.-C., M.H., M.S. and H.L.; Data curation, D.D., M.-J.C.-C., T.O., M.H., M.S. and H.L.; Formal analysis, D.D., M.H. and H.L.; Funding acquisition, M.S. and H.L.; Investigation, D.D., M.-J.C.-C., T.O. and M.S.; Methodology, D.D., M.-J.C.-C., T.O., M.S. and H.L.; Project administration, M.H.; Resources, H.L.; Supervision, D.D.; Writing—original draft, D.D.; Writing—review \& editing, D.D., M.-J.C.-C., T.O., M.H., M.S. and H.L. All authors have read and agreed to the published version of the manuscript.

Funding: This research received no external funding.

Acknowledgments: We thank Margareta Sprycha at the National Veterinary Institute (SVA) for her hard work with the bioanalysis.

Conflicts of Interest: The authors declare no conflicts of interest.

\section{Abbreviations}

AME-absorption-modifying excipient, $\mathrm{CL}_{\mathrm{Cr}-\mathrm{EDTA}}$-clearance of ${ }^{51} \mathrm{Cr}$-EDTA, $\mathrm{P}_{\text {eff }}$-intestinal effective permeability, PE—-permeation enhancer, SDS—sodium dodecyl sulfate, SPIP—single-pass intestinal perfusion

\section{References}

1. Amidon, G.L.; Sinko, P.J.; Fleisher, D. Estimating human oral fraction dose absorbed: A correlation using rat intestinal membrane permeability for passive and carrier-mediated compounds. Pharm. Res. 1988, 5, 651-654. [CrossRef] 
2. Cao, X.; Gibbs, S.T.; Fang, L.; Miller, H.A.; Landowski, C.P.; Shin, H.-C.; Lennernas, H.; Zhong, Y.; Amidon, G.L.; Lawrence, X.Y. Why is it challenging to predict intestinal drug absorption and oral bioavailability in human using rat model. Pharm. Res. 2006, 23, 1675-1686. [CrossRef]

3. Dubbelboer, I.; Dahlgren, D.; Sjögren, E.; Lennernäs, H. Rat intestinal drug permeability: A status report and summary of repeated determinations. Eur. J. Pharm. Biopharm. 2019, 142, 364-376. [CrossRef]

4. Dahlgren, D.; Roos, C.; Lundqvist, A.; Abrahamsson, B.; Tannergren, C.; Hellström, P.M.; Sjögren, E.; Lennernäs, H. Regional intestinal permeability of three model drugs in human. Mol. Pharm. 2016, 13, 3013-3021. [CrossRef]

5. Dahlgren, D.; Roos, C.; Peters, K.; Lundqvist, A.; Tannergren, C.; Sjögren, E.; Sjöblom, M.; Lennernäs, H. Evaluation of drug permeability calculation based on luminal disappearance and plasma appearance in the rat single-pass intestinal perfusion model. Eur. J. Pharm. Biopharm. 2019, 142, 31-37. [CrossRef] [PubMed]

6. Buckley, S.T.; Bækdal, T.A.; Vegge, A.; Maarbjerg, S.J.; Pyke, C.; Ahnfelt-Rønne, J.; Madsen, K.G.; Schéele, S.G.; Alanentalo, T.; Kirk, R.K. Transcellular stomach absorption of a derivatized glucagon-like peptide-1 receptor agonist. Sci. Transl. Med. 2018, 10, eaar7047. [CrossRef] [PubMed]

7. Tyagi, P.; Pechenov, S.; Subramony, J.A. Oral peptide delivery: Translational challenges due to physiological effects. J. Control. Release 2018, 287, 167-176. [CrossRef] [PubMed]

8. Petersen, S.B.; Nielsen, L.G.; Rahbek, U.L.; Guldbrandt, M.; Brayden, D.J. Colonic absorption of salmon calcitonin using tetradecyl maltoside (TDM) as a permeation enhancer. Eur. J. Pharm. Sci. 2013, 48, 726-734. [CrossRef] [PubMed]

9. Rubinstein, A.; Tirosh, B.; Baluom, M.; Nassar, T.; David, A.; Radai, R.; Gliko-Kabir, I.; Friedman, M. The rationale for peptide drug delivery to the colon and the potential of polymeric carriers as effective tools. $J$. Control. Release 1997, 46, 59-73. [CrossRef]

10. Dahlgren, D.; Sjöblom, M.; Lennernäs, H. Intestinal absorption-modifying excipients: A current update on preclinical in vivo evaluations. Eur. J. Pharm. Biopharm. 2019, 142, 411-420. [CrossRef]

11. Dahlgren, D.; Sjöblom, M.; Hedeland, M.; Lennernäs, H. The in vivo effect of transcellular permeation enhancers on the intestinal permeability of two peptide drugs enalaprilat and hexarelin. Pharmaceutics 2020, 2, 99. [CrossRef] [PubMed]

12. Dahlgren, D.; Roos, C.; Lundqvist, A.; Langguth, P.; Tannergren, C.; Sjöblom, M.; Sjögren, E.; Lennernas, H. Preclinical effect of absorption modifying excipients on rat intestinal transport of five model compounds and the intestinal barrier marker 51Cr-EDTA. Mol. Pharm. 2017, 14, 4243-4251. [CrossRef] [PubMed]

13. Nylander, O.; Sababi, M.; Bark, J. Characterization of 51Cr-EDTA as a marker of duodenal mucosal permeability. Acta Physiologica 1991, 143, 117-126. [CrossRef] [PubMed]

14. Winiwarter, S.; Bonham, N.M.; Ax, F.; Hallberg, A.; Lennernäs, H.; Karlén, A. Correlation of human jejunal permeability (in vivo) of drugs with experimentally and theoretically derived parameters. A multivariate data analysis approach. J. Med. Chem. 1998, 41, 4939-4949. [CrossRef] [PubMed]

15. Lennernäs, H.; Gjellan, K.; Hällgren, R.; Graffner, C. The influence of caprate on rectal absorption of phenoxymethylpenicillin: Experience from an in-vivo perfusion in humans. J. Pharm. Pharmacol. 2002, 54, 499-508. [CrossRef]

16. Nylander, O.; Kvietys, P.; Granger, D.N. Effects of hydrochloric acid on duodenal and jejunal mucosal permeability in the rat. Am. J. Physiol. Gastrointest. Liver Physiol. 1989, 257, G653-G660. [CrossRef]

17. Roos, C.; Dahlgren, D.; Sjögren, E.; Sjöblom, M.; Hedeland, M.; Lennernäs, H. Effects of absorption-modifying excipients on jejunal drug absorption in simulated fasted and fed luminal conditions. Eur. J. Pharm. Biopharm. 2019, 142, 387-395. [CrossRef]

18. Sjögren, E.; Dahlgren, D.; Roos, C.; Lennernas, H. Human in vivo regional intestinal permeability: Quantitation using site-specific drug absorption data. Mol. Pharm. 2015, 12, 2026-2039. [CrossRef]

19. Dahlgren, D.; Roos, C.; Johansson, P.; Lundqvist, A.; Tannergren, C.; Abrahamsson, B.; Sjögren, E.; Lennernäs, H. Regional intestinal permeability in dogs: Biopharmaceutical aspects for development of oral modified-release dosage forms. Mol. Pharm. 2016, 13, 3022-3033. [CrossRef]

20. Roos, C.; Dahlgren, D.; Tannergren, C.; Abrahamsson, B.; Sjögren, E.; Lennernas, H. Regional intestinal permeability in rats: A comparison of methods. Mol. Pharm. 2017, 14, 4252-4261. [CrossRef] [PubMed]

21. Roos, C.; Dahlgren, D.; Berg, S.; Westergren, J.; Abrahamsson, B.; Tannergren, C.; Sjögren, E.; Lennernäs, H. In Vivo Mechanisms of Intestinal Drug Absorption from Aprepitant Nanoformulations. Mol. Pharm. 2017, 14, 4233-4242. [CrossRef] [PubMed] 
22. Davies, B.; Morris, T. Physiological parameters in laboratory animals and humans. Pharm. Res. 1993, 10, 1093-1095. [CrossRef] [PubMed]

23. de Lannoy, I.A.; Barker III, F.; Pang, K.S. Formed and preformed metabolite excretion clearances in liver, a metabolite formation organ: Studies on enalapril and enalaprilat in the single-pass and recirculating perfused rat liver. J. Pharm. Biopharm. 1993, 21, 395-422. [CrossRef] [PubMed]

24. Roumi, M.; Marleau, S.; du Souich, P.; Maggi, T.; Deghenghi, R.; Ong, H. Kinetics and disposition of hexarelin, a peptidic growth hormone secretagogue, in rats. Drug Metab. Dispos. 2000, 28, 44-50.

25. Dahlgren, D.; Roos, C.; Lundqvist, A.; Tannergren, C.; Sjöblom, M.; Sjögren, E.; Lennernas, H. Effect of absorption-modifying excipients, hypotonicity, and enteric neural activity in an in vivo model for small intestinal transport. Int. J. Pharm. 2018, 549, 239-248. [CrossRef]

26. Dahlgren, D.; Roos, C.; Johansson, P.; Tannergren, C.; Lundqvist, A.; Langguth, P.; Sjöblom, M.; Sjögren, E.; Lennernas, $\mathrm{H}$. The effects of three absorption-modifying critical excipients on the in vivo intestinal absorption of six model compounds in rats and dogs. Int. J. Pharm. 2018, 547, 158-168. [CrossRef]

27. Dahlgren, D.; Roos, C.; Lundqvist, A.; Tannergren, C.; Sjöblom, M.; Sjögren, E.; Lennernäs, H. Time-dependent effects on small intestinal transport by absorption-modifying excipients. Eur. J. Pharm. Biopharm. 2018, 132, 19-28. [CrossRef]

28. Paradissis, G.N.; Garegnani, J.A.; Whaley, R.S. Extended Release Pharmaceutical Formulations. U.S. Patent 5,133,974, 28 July 1992.

29. Wang, Y.T.; Mohammed, S.D.; Farmer, A.D.; Wang, D.; Zarate, N.; Hobson, A.R.; Hellström, P.M.; Semler, J.R.; Kuo, B.; Rao, S.S. Regional gastrointestinal transit and pH studied in 215 healthy volunteers using the wireless motility capsule: Influence of age, gender, study country and testing protocol. Aliment. Pharmacol. Ther. 2015, 42, 761-772. [CrossRef]

30. Dahlgren, D.; Roos, C.; Sjögren, E.; Lennernäs, H. Direct In Vivo Human Intestinal Permeability (Peff) Determined with Different Clinical Perfusion and Intubation Methods. J. Pharm. Sci. 2014, 104, 2702-2726. [CrossRef]

31. Fagerholm, U.; Lindahl, A.; Lennernäs, H. Regional intestinal permeability in rats of compounds with different physicochemical properties and transport mechanisms. J. Pharm. Pharmacol. 1997, 49, 687-690. [CrossRef]

32. Sutton, S.C.; Evans, L.A.; Fortner, J.H.; McCarthy, J.M.; Sweeney, K. Dog colonoscopy model for predicting human colon absorption. Pharm. Res. 2006, 23, 1554-1563. [CrossRef] [PubMed]

33. Lozoya-Agullo, I.; González-Álvarez, I.; González-Álvarez, M.; Merino-Sanjuán, M.; Bermejo, M. In situ perfusion model in rat colon for drug absorption studies: Comparison with small intestine and Caco-2 cell model. J. Pharm. Sci. 2015, 104, 3136-3145. [CrossRef] [PubMed]

34. Bransford, P.; Cook, J.; Gupta, M.; Haertter, S.; He, H.; Ju, R.; Kanodia, J.; Lennernäs, H.; Lindley, D.; Polli, J.E. ICH M9 Guideline in development on Biopharmaceutics Classification System-based biowaivers: An Industrial Perspective from the IQ Consortium. Mol. Pharm. 2019, 17, 361-372. [CrossRef] [PubMed]

35. Thomae, A.V.; Wunderli-Allenspach, H.; Krämer, S.D. Permeation of aromatic carboxylic acids across lipid bilayers: The pH-partition hypothesis revisited. Biophys. J. 2005, 89, 1802-1811. [CrossRef]

36. Dahlgren, D.; Lennernäs, H. Intestinal Permeability and Drug Absorption: Predictive Experimental, Computational and In Vivo Approaches. Pharmaceutics 2019, 11, 411. [CrossRef]

37. Yamamoto, A.; Taniguchi, T.; Rikyuu, K.; Tsuji, T.; Fujita, T.; Murakami, M.; Muranishi, S. Effects of various protease inhibitors on the intestinal absorption and degradation of insulin in rats. Pharm. Res. 1994, 11, 1496-1500. [CrossRef]

38. Wu, L.; Zhang, G.; Lu, Q.; Sun, Q.; Wang, M.; Li, N.; Gao, Z.; Sun, Y.; Li, T.; Han, D. Evaluation of salmon calcitonin (sCT) enteric-coated capsule for enhanced absorption and GI tolerability in rats. Drug Dev. Ind. Pharm. 2010, 36, 362-370. [CrossRef]

39. Lipinski, C.A.; Lombardo, F.; Dominy, B.W.; Feeney, P.J. Experimental and computational approaches to estimate solubility and permeability in drug discovery and development settings. Adv. Drug Deliv. Rev. 1997, 23, 3-25. [CrossRef]

40. Fetih, G.; Lindberg, S.; Itoh, K.; Okada, N.; Fujita, T.; Habib, F.; Artersson, P.; Attia, M.; Yamamoto, A. Improvement of absorption enhancing effects of $n$-dodecyl- $\beta$-D-maltopyranoside by its colon-specific delivery using chitosan capsules. Int. J. Pharm. 2005, 293, 127-135. [CrossRef] 
41. Ishizawa, T.; Hayashi, M.; Awazu, S. Enhancement of jejunal and colonic absorption of fosfomycin by promoters in the rat. J. Pharm. Pharmacol. 1987, 39, 892-895. [CrossRef]

42. Maher, S.; Wang, X.; Bzik, V.; McClean, S.; Brayden, D.J. Evaluation of intestinal absorption and mucosal toxicity using two promoters. II. Rat instillation and perfusion studies. Eur. J. Pharm. Sci. 2009, 38, 301-311. [CrossRef] [PubMed]

43. Murakami, M.; Kusanoi, Y.; Takada, K.; Muranishi, S. Assessment of enhancing ability of medium-chain alkyl saccharides as new absorption enhancers in rat rectum. Int. J. Pharm 1992, 79, 159-169.

44. Muranushi, N.; Mack, E.; Kim, S. The effects of fatty acids and their derivatives on the intestinal absorption of insulin in rat. Drug Dev. Ind. Pharm. 1993, 19, 929-941. [CrossRef]

45. Maher, S.; Mrsny, R.J.; Brayden, D.J. Intestinal permeation enhancers for oral peptide delivery. Adv. Drug Deliv. Rev. 2016, 106, 277-319. [CrossRef]

(C) 2020 by the authors. Licensee MDPI, Basel, Switzerland. This article is an open access article distributed under the terms and conditions of the Creative Commons Attribution (CC BY) license (http://creativecommons.org/licenses/by/4.0/). 